\title{
EDUCATION RIGHTS IN THE BILL OF RIGHTS
}

\section{Elizabeth Craig, Research Student and Laura Lundy, Senior Lecturer, School of Law, Queen's University Belfast \\ INTRODUCTION}

The fact that the Northern Ireland Human Rights Commission (NIHRC) prioritised education rights from the outset of its Bill of Rights consultation should come as no surprise to anyone with any knowledge of the Northern Ireland education system. The Northern Irish school system is unusual from a number of perspectives. Most significant of these is the fact that it is almost completely religiously segregated with Catholic pupils attending voluntary schools run by the Catholic church and Protestant children for the most part attending non-denominational state schools. ${ }^{1}$ The fact that schools are divided by religion in such a visible way has allowed them to be used as a focal point for public protest and controversy. ${ }^{2}$ Added to this, there has been a growing demand for alternative provision by parents who want their children to be educated in mixed religious (integrated) schools or through the medium of the Irish language. And finally, at secondary level there is a controversial system of academic selection at the age of eleven which recent research has shown contributes further to Northern Ireland's complex social and economic problems. ${ }^{3}$ In effect, schools provide a venue in which the jurisdiction's religious, political and social divisions find a public outlet and therefore a setting in which claims that human rights are being infringed arise frequently. Although the European Convention on Human Rights contains an explicit right to education, ${ }^{4}$ it has been subject to a highly restrictive interpretation by the European Court of Human Rights, ${ }^{5}$ with the result that it fails for the most part to address the complex problems generated by Northern Ireland's school system. ${ }^{6}$ The objective of this article is to examine critically the proposals by the NIHRC to supplement the ECHR and in particular to assess the extent to which the recommendations

1 For further details of this and an explanation of how it came about, see L. Lundy, Education Law, Policy and Practice in Northern Ireland, (2000, SLS) pp 4-7.

2 In recent years this has included the walk-outs by pupils at various state schools in response to the appointment of Sinn Fein's Martin McGuinness as Minister for Education alongside the protests outside Catholic schools by parents opposed to the RUC having been invited to speak to pupils about drugs. Most recently, attention has focused on the loyalist protests at the Catholic Holy Cross primary school.

3 A.M. Gallagher and A. Smith, The Effects of the Selective System of Secondary Education in Northern Ireland - Main Report (2000 DE).

4 Article 2 of the First Protocol - "no person shall be denied the right to education. In the exercise of any functions which it assumes in relation to education and teaching, the state shall respect the right of parents to ensure such education and teaching in accordance with their own religious and philosophical convictions."

5 See in particular, The Belgian Linguistic Case (1968) 1 EHRR 252, where the European Court of Human Rights considered that the right was one of access to whatever schools the State had in its discretion decided to provide.

6 See for example, $X \mathrm{v}$ United Kingdom (1978) 14 DR 179, where a complaint about the funding arrangements for integrated schools was considered inadmissible. 
reflect both the particular circumstances of Northern Ireland's education system and relevant international human rights covenants.

\section{The Right To An Effective Education}

The NIHRC has proposed that "everyone has the right to an effective education." What constitutes an effective education for each child is to be determined in accordance with 'the best interests' principle, which is elaborated upon in the chapter on children's rights. ${ }^{8}$ This proposal appears to require that the educational needs of those who are particularly vulnerable, including children with special educational needs, those who are pregnant, in care or in the juvenile justice system, are properly ascertained and addressed. It recognises that an effective education should be directed towards "the full development of the person, including his or her talents, mental and physical abilities and sense of dignity" and should enable "all persons to participate effectively in the life of the community." These aims are similar to some of those included in a number of human rights instruments, in particular Article 29(1) of the United Nations Convention on the Rights of the Child $(\mathrm{UNCRC})^{10}$ and Article 13(1) of the International Covenant on Economic, Social and Cultural Rights. ${ }^{11}$ The reference to the "development of the person" is "intended to cover the many aspects important to human growth, such as intellectual, spiritual, physical, emotional, moral, creative and aesthetic development," ${ }^{\prime 2}$ an interpretation which reflects wide-spread dissatisfaction with the academic focus of the current curriculum ${ }^{13}$ and the system of academic selection at the age of $11 .{ }^{14}$ The second aim is an extended version of the traditional idea that education should prepare children for "the opportunities, responsibilities and experiences of adult life," 15 (emphasis added) an acknowledgement of the fact that children should be prepared for effective participation in the life of the community

7 Proposal 11(a)(2).

8 NIHRC (2001) p 74. See Proposal 10(a)(2) "In all actions concerning children, whether undertaken by public or private institutions, individuals or bodies, courts of law, administrative or legislative authorities, the best interests of the child shall be the paramount consideration". Cf. Article 3(1) UN Convention on the Rights of the Child - "In all actions concerning children. . . the best interests of the child shall be a primary consideration."

9 Proposal 11(a)(2)

10 Article 29(1)(a) - "the development of the child's personality, talents and mental and physical abilities to their fullest potential." Article 29(1)(d) - "the preparation of the child for responsible life in a free society."

11 Article 13(1) - "education shall be directed to the full development of the human personality and the sense of its dignity... (and) shall enable all persons to participate effectively in a free society. .."

12 NIHRC (2001) p 74

13 The Northern Ireland Council for the Curriculum, Examinations and Assessment (NICCEA) is currently consulting on proposals for a new Northern Ireland Curriculum. For further information, see NICCEA website at www.ccea.org.uk, last visited 31 October 2001.

14 The Burns Report has recommended the abolition of the current system of selection. (Para 9.7, 'Education for the $21^{\text {st }}$ Century: Post Primary Review Body' (Bangor, Department of Education, 2001).

15 See Article 4 Education Reform (Northern Ireland) Order 1989. 
throughout their lives. ${ }^{16}$ The right is limited by the phrase "to the greatest extent possible." This appears to be in recognition of the fact that the delivery of an effective education for each individual will depend both on his or her receptiveness and on the availability of resources to meet his or her needs with no particular outcome being guaranteed for any individual.

\section{Rights of Parents}

The NIHRC has proposed that the State "shall, to the greatest extent possible, ensure the right of parents to have education and teaching for their children in conformity with their religious, philosophical and pedagogical convictions, subject to the competence of the child to decide for him or herself in accordance with his or her age and maturity." 17 This proposal has obvious similarities with the second sentence of Article 2 of the First Protocol of the ECHR. ${ }^{18}$ The key difference is an additional reference to 'pedagogical convictions', included as a result of the limited interpretation of the term 'religious and philosophical convictions' adopted by the European Court of Human Rights.' 19 The term "pedagogical", defined in the Glossary as "beliefs about how a person should be taught or receive education," also appears in the European Union Charter of Fundamental Rights ${ }^{20}$ and could be interpreted to include convictions concerning the education of children with special educational needs, language and integrated education. However, the NIHRC has chosen to highlight the fact that the term was included to provide a right to integrated education, ${ }^{21}$ thereby raising doubts about whether it is also intended to cover these other convictions. The NIHRC has stated that the State should ensure parents' rights "to the greatest extent possible." It is unclear whether it is the NIHRC's intention to override the effects of the UK's reservation to the second sentence of Article 2 of the First Protocol of the ECHR, which would be highly controversial politically, or whether it is implicit that the rights of parents will be ensured "only so far as it is compatible with the provision of efficient education and training, and the avoidance of unreasonable public expenditure."

16 In a similar vein the NICCEA has proposed that education should aim "to enable young people to achieve their potential and to make informed and responsible choices and decisions throughout their lives." (Para 1.2, "Northern Ireland Curriculum Review. Phase I Consultation. Proposals for Changes to Northern Ireland Curriculum Framework April-June 2000' (Belfast, NICCEA, 2000)).

17 Proposal 11(a)(3).

18 "In the exercise of any functions which it assumes in relation to education and to teaching the State shall respect the right of parents to ensure such education and teaching in conformity with their own religious and philosophical convictions."

19 NIHRC (2001) p 75 Parental views concerning the use of corporal punishment in school were considered to be philosophical convictions in the case of Campbell \& Cosans v UK (1982) 4 EHRR 293, para 37. However, there has otherwise been a notable lack of cases brought successfully under the second sentence of Article 2. See, for example, The Belgian Linguistic Case supra $\mathrm{n} 5$.

20 Article 14(3) - "The freedom to found educational establishments with due respect for democratic principles and the right of parents to ensure the education and teaching of their children in conformity with their religious, philosophical and pedagogical convictions shall be respected, in accordance with the national laws governing the exercise of such freedom and right."

21 NIHRC (2001) p 75 
The qualifying reference in the first sentence, which indicates that parents' rights are subject to the right of the child to decide for him or herself could also be controversial. Proposals in the children's rights chapter recognise the right of the child to participate effectively in matters concerning his or her education (Proposal 10(i)(4)) and to be given an opportunity to express his or her views and to have them given due weight (Proposal 10(b)(1)) but the wording used here seems to imply that once the child has reached a certain age and maturity, he or she could make unilateral decisions about his or her education, a state of affairs which could itself be considered a violation of the right of parents under the second sentence of Article 2 of the First Protocol of the ECHR. The Committee on the Rights of the Child, in response to the United Kingdom's initial report under the UNCRC, expressed concern that children were not systematically invited to express their opinions on matters such as sex and religious education as required under Article 12 of the Convention ${ }^{22}$ but the NIHRC 's proposal would go further, by enabling some children to unilaterally apply for exemption from religious education and collective worship against parental wishes.

The second sentence of the proposal provides that the State shall "respect the right of parents to choose for their children education in schools with a particular religious ethos, education in integrated schools and education in Irish-medium schools." 23 The intention here is to extend the remit of the second sentence of Article 2 of the First Protocol to include a right of choice in the three designated areas. This goes beyond the established jurisprudence of the Strasbourg organs, which is that Article 2 does not require the State to provide or subsidise education of any particular type or level. ${ }^{24}$ It is interesting that the limitation on parental rights in the first sentence of the proposal (i.e. "to the greatest extent possible") has not been expressly included in the second sentence, raising an issue as to whether the right of choice is intended to be absolute. On the other hand it could be argued that the obligation on the State in the second sentence is simply to 'respect' the right of parents to choose and not to 'ensure' that the child will be admitted to the school of their choice.

\section{Language Rights}

The fact that Irish is the only language specifically mentioned in the chapter on education rights is difficult to understand in view of the fact that the NIHRC has elsewhere identified the need to guarantee the rights of all ethnic communities. ${ }^{25}$ Indeed the NIHRC, drawing on the Framework Convention for the Protection of National Minorities, has recommended in the chapter on language rights that legislation be introduced to ensure for members of all linguistic communities, where there is sufficient demand, the right to learn

22 Para 14, 'Concluding observations of the Committee on the Rights of the Child: United Kingdom of Great Britain and Northern Ireland' UN Doc. CRC/C/15/Add:,34 (1995) Article 12 UNCRC: "States Parties shall assure to the child who is capable of forming his or her own views the right to express those views freely in all matters affecting the child, the views of the child being given due weight in accordance with the age and maturity of the child."

23 Proposal 11(a)(3).

24 The Belgian Linguistic Case (1968) 1 EHRR 252.

25 See Chapter 3. 
their language and to be educated in and through it. ${ }^{26}$ The aim of this proposal is to protect those belonging to the Chinese, Urdu and Traveller communities and to encourage the use of criteria to determine when sufficiency of demand exists. ${ }^{27}$ However, it would perhaps make more sense if convictions concerning the language of education or the provision of opportunities for learning a minority language within English-medium schools were recognised as pedagogical convictions in the chapter on education rights. Alternatively, the NIHRC could expressly recognise the right to education in and/or through a minority language, subject to sufficiency of demand, as opposed to making legislative recommendations. This would also provide protection for speakers of Ulster Scots, recognised as a minority language under Part II of the European Charter for Regional or Minority Languages. ${ }^{28}$

\section{School Funding}

The NIHRC has recommended that the State should provide financial support to schools "on an equitable and transparent basis, subject to reasonable requirements, including minimum numbers of pupils in any area and without prejudice to the need to address inequalities." 29 This goes beyond anything in the ECHR or even the Framework Convention on National Minorities. ${ }^{30}$ Its inclusion is justified by the fact that allegations about discrimination in funding have dogged the education system for years. In the past, concerns have been expressed about both the level of funding for existing schools as well as the criteria used to decide when to fund new schools. These have manifested themselves in litigation, ${ }^{31}$ research reports

26 Proposal 13(5)(f). Cf. Art 14(2) Framework Convention for the Protection of National Minorities - "In areas inhabited by persons belonging to national minorities traditionally or in substantial numbers, if there is sufficient demand, the Parties shall endeavour to ensure, as far as possible and within the framework of their education systems, that persons belonging to those minorities have adequate opportunities for being taught in the minority language or for receiving instruction in this language."

27 NIHRC (2001) p 83

28 Under Article 7(1)(f) \& (g) of the Charter, the UK has undertaken to base its policies, legislation and practice on certain objectives and principles, including the provision of appropriate forms and means for the teaching and study of UlsterScots and the provision of facilities enabling non-speakers to learn it. Cf. the fact that the UK has undertaken to promote the Irish language in Northern Ireland by making available either primary and/or secondary education, a substantial part of primary and/or secondary education or to provide for the teaching of Irish as an integral part of the curriculum at least to those pupils who or whose families so request and "whose number is considered sufficient" under Part III of the same Charter (Article 8(1)(b)(iv) \& (c)(iv)).

29 Chapter $11,4$.

30 Article 2 of the First Protocol in conjunction with Article 14 ECHR only requires that, if the State does subsidise education of a particular type or level, it should not do so in a discriminatory way. See Belgian Linguistics Case (1968) 1 EHRR 252.

31 See In re Daly's Application (unreported, October 5 1990) in which the Catholic Bishops claimed unsuccessfully that the funding formula for grant-maintained integrated schools discriminated against Catholics. 
by the Standing Advisory Commission on Human Rights, ${ }^{32}$ and ultimately legislative change which enables voluntary schools (the majority of which are Catholic) to opt for $100 \%$ funding of capital costs. ${ }^{33}$ Further changes are underway. In particular, there are ongoing reviews of both the system of financial allocation for recurrent expenditure ${ }^{34}$ and the viability criteria for establishing new Irish medium and integrated schools. ${ }^{35}$ For these reasons, an overriding requirement for funding to be "equitable and transparent" should be welcomed by most in the education sector. The reception which the rest of the proposal is likely to receive is less certain, particularly the reservation that the obligation should be "without prejudice to the need to redress past inequalities". This proactive approach to tackling inequalities is already established in the school funding system by virtue of the various New Targeting Social Need initiatives. It might also facilitate the implementation of the recommendation of the Burns Report that extra funding should be deployed to improve the standard of accommodation in some schools because this has a bearing "on their status and the esteem of pupils" ${ }^{36}$ However, any suggestion that the clause would enable preferential funding to be given to specific sectors such as integrated and Irish medium schools, might well be interpreted as a means of disadvantaging the traditional controlled and voluntary sectors and subject to controversy.

\section{Access to Education}

The NIHRC has recommended that "no child shall be denied access to school" on any of the grounds which it proposes to include in its general anti-discrimination clause. ${ }^{37}$ This would extend the heads of discrimination to matters such as family status and sexual orientation which are not expressly covered by the ECHR or the UNESCO Convention on the Elimination of Discrimination in Education. Most significant in the context of education, however, would be the fact that it would include protection against both direct and indirect discrimination, since the latter is not otherwise covered explicitly by Article 14 of the ECHR. ${ }^{38}$ The prohibition of indirect discrimination on the grounds of religion in a system which is almost completely religiously segregated could well have far reaching effects on a number of issues which impinge on access to education such as admissions policies, school closures and funding. The NIHRC has indicated that there would need to be exceptions for schools with a particular religious ethos to

32 See R. Cormack, A. Gallagher and R. Osborne, 'Religious Affiliation and Educational Attainment in Northern Ireland: the Financing of Schools in Northern Ireland' Annex E in the Sixteenth Report of the Standing Advisory Commission on Human Rights (1990-91) (London, HMSO 1991).

33 Education (NI) Order 1993, art 28. Prior to this, the maximum assistance a voluntary school could receive for capital costs was $85 \%$.

34 Common Funding Formula for Grant-aided Schools - a consultation (DE, 2001)

35 Review of Viability Criteria for Irish Medium and Integrated Schools (DE, 2000).

36 Op cit $\mathrm{n} 14, \mathrm{p} 29$.

37 Chapter 4, 4

38 Nevertheless rules which are neutral on their face but impact adversely on a particular group may be susceptible to challenge under Article 14. See S. Livingstone, (1997) 'Article 14 and the Prevention of Discrimination in the European Convention on Human Rights' 1 EHRLR 25-34, at 30. 
use criteria "within the mission of the school". ${ }^{39}$ In the past denominational schools in Northern Ireland have not used religious-based criteria - there was little need for them as few Protestant children applied to Catholic schools and vice versa. Whether church-owned schools will refrain from using them in the future is uncertain. The Burns Report has recommended that school admissions be determined by a centralised list of criteria which focus on matters such as parental choice, siblings and home to school distance. ${ }^{40}$ These are likely to be seen to be unduly restrictive by schools (and parents) and this may result in calls for ethos-related criteria to be permitted. While faith schools may feel they have no choice but to go down this line, few people involved in education would see this as a positive way forward, particularly if it results in the type of admissions policies which are prevalent in church schools in England. ${ }^{41}$

One of the specific questions which has been put out for consultation is whether the Bill of Rights should require "the state to ensure that admission criteria for educational establishments ensure access to effective education."42 Any such proposal cannot be traced directly to any particular international human rights obligation. It arises out of the widespread concern about the fairness of the 11 plus $^{43}$ and current admissions policies employed in Northern Ireland's schools. ${ }^{44}$ However, genuine as these concerns are, it is difficult to see how the proposed clause might address them. The construction of the proposed right is awkward - admissions criteria cannot in themselves ensure access to an effective education for all. The best they can do is to ensure that when choices are made, they can be reasonably justified. Moreover, other recommendations in relation to a right to an effective education and a right not to be discriminated against in access to education would seem to have this covered. If everyone is assured an effective education and there are no unjustifiable barriers hindering their admission to individual educational establishments, it is difficult to see what additional protection someone might get from the proposal. In its explanation, the NIHRC has said that the proposal is intended to ensure that selection criteria "should be subjected to external review on the grounds of their impact on the delivery of effective education for all." ${ }^{45}$ This might have been better expressed as a direct proposal. There is no doubt that there is a strong argument for introducing a system of monitoring the impact of school admissions policies. ${ }^{46}$ Although this is going to occur to some extent as a result of the statutory equality duty in section 75 of the Northern Ireland Act

39 They have also accepted the need for exceptions for single sex schools. This is the position in domestic sex discrimination legislation. See Sex Discrimination (NI) Order 1976, art 27.

40 Education for the $21^{\text {st }}$ Century, Report of the Post-Primary Review Body, (October 2001, DE).

41 In England and Wales schools use criteria designed to measure the extent of religious commitment such as the number of church attendances, participation in church activities, the parish council etc.

42 Question 29.

43 Op cit $\mathrm{n} 3$.

44 See L. Lundy, Access to Secondary Schools in Northern Ireland (NIHRC 2001).

45 Chapter 11(b) 2.

46 See L. Lundy, Access to Secondary Schools in Northern Ireland (NIHRC 2001), pp 40-41. 
1998 , there is a case for broadening the remit of the review to include an examination of the other issues which affect access to education.

\section{Human Rights Education}

The NIHRC's recommendation that "education in all its forms shall be directed to the promotion of human rights, equality, dignity of the person, respect for diversity and tolerance" 47 meets the requirements of several international instruments which identify the strengthening of respect for human rights as one of a number of educational aims. ${ }^{48}$ It might therefore have been more appropriate if the reference to human rights education was inserted alongside the identification of educational goals in Proposal 11(a)(2). The NIHRC's recognition that this proposal will require the inclusion of specific provisions on education about national and international human rights standards in the Northern Ireland Curriculum ${ }^{49}$ also reflects the current position of the UN Committee on the Rights of the Child. ${ }^{50}$ However, what is not mentioned is that the promotion of human rights within schools may also require a change of educational ethos in Northern Ireland. The need for such an ethos was recognised by the UN Committee on the Rights of the Child when it recommended in its response to the UK's initial report that teaching methods in the UK be inspired by and reflect the spirit and philosophy of the UNCRC. ${ }^{51}$ More recently the Committee on the Rights of the Child has recommended that values and policies conducive to human rights be promoted within schools on issues such as bullying and discipline and has also advocated "the participation of children in school life, the creation of school communities and student councils, peer education and peer counselling, and the involvement of children in school disciplinary proceedings...as part of the process of learning and experiencing the realization of rights" (emphasis added). ${ }^{52}$

\section{The Employment of Teachers}

As Northern Ireland's domestic legislation currently stands, the employment of teachers is not subject to the stringent requirements of the Fair Employment and Treatment (NI) Order 1998 in respect of religious and political discrimination. ${ }^{53}$ The NIHRC has not made a specific proposal regarding this exemption. However, it does question whether it should be

47 Proposal 11(c).

48 E.g. Article 26(2) UDHR \& Article 13(1) ICESCR which recognise that education should be directed to the strengthening of respect for human rights and fundamental freedoms and should promote understanding, tolerance and friendship.

49 NIHRC (2001) p 76.

50 According to the Committee, human rights education should provide information on the content of human rights treaties. (Para 15, 'Convention on the Rights of the Child General Comment 1, The Aims of Education' (2000) UN Doc. CRC/GC/2001/1).

51 Para 32, 'Concluding observations of the Committee on the Rights of the Child: United Kingdom of Great Britain and Northern Ireland' (1995) UN Doc CRC/C/15/Add.34.

52 Paras 8 \& 19, 'Convention on the Rights of the Child General Comment 1, The Aims of Education' (2000) UN Doc. CRC/GC/2001/1.

53 S 71. The Equality Commission is required to keep the exemption under review. 
removed and offers a provisional recommendation that it should be restricted to situations where there is a "genuine occupational qualification." The issue has been part of a recent consultation on the proposed Single Equality Bill for Northern Ireland. ${ }^{54}$ Moreover, it has already been addressed by the European Union's Framework Directive on Equal Treatment in Employment and Occupation which prohibits discrimination in schools on the basis of religion or belief other than where it is a genuine occupational requirement. ${ }^{55}$ The Framework Directive includes a specific exemption for Northern Ireland in relation to the recruitment (note - not promotion) of teachers "in order to maintain a balance of opportunity in employment for teachers in Northern Ireland while furthering the reconciliation of historical divisions between the major religious communities." 56 Any change to the exemption would be controversial, as it is essentially an endorsement of the Catholic Church's desire to employ Catholic teachers in its schools. In reality, the issue is likely to be determined by the outcome of the consultation on the Single Equality Bill rather than the Bill of Rights. Nonetheless, the NIHRC's tentative proposal is one possible outcome from that process. ${ }^{57}$ If the exemption for the recruitment of teachers were to be confined to situations where religion or belief is a genuine occupational requirement, the impact within the education system may be more symbolic than real as Protestant teachers are unlikely to seek employment in droves in Catholic schools. However, at that stage the discussion will undoubtedly have been transformed into a debate about what actually constitutes a genuine occupational qualification.

\section{Children's Rights In Education.}

The NIHRC has to be commended for producing such a detailed document on so many complex and controversial issues in a relatively short time. However, given the scale of the task, it is inevitable that the proposals at times do not read as a cohesive whole. One example of this is the fact that not all of the education rights are in the education chapter. ${ }^{58}$ There are several quite significant education rights in the chapter on children's rights. For instance, it is proposed that a child should be guaranteed effective participation in matters affecting his or her education, which is a strengthened version of Article 12 of the UNCRC. The reasons why the education rights have been dispersed in this way are not entirely clear. ${ }^{59}$ However, what is more problematic is that the rights in Chapter 10 (children's rights) have at times a quite different character to the rights in

54 Promoting Equality of Opportunity: A Single Equality Bill for Northern Ireland (OFMDFM, 2001).

55 Council Directive 2000/78/EC

56 Ibid art 15.

57 The other potential outcome is the retention of the status quo so far as recruitment is concerned.

58 It is understandable that language rights in education appear in the language chapter. A cross-reference might, however, have been helpful.

59 The NIHRC says that the rights in chapter 10 are those of particular importance to children. However, it is difficult to separate rights in this way, especially given that the main rights to an effective education and non-discrimination in access are in Chapter 11. 
chapter 11 (education). For example, Chapter 10 includes the following proposal:

"School exclusions shall be imposed only as a last resort. Every child excluded from school has the right to be informed promptly of the grounds for exclusion, to receive all documentation relating to the school's decision to exclude and to have the right to participate in an independent appeal procedure, together with his or her parents, guardians or other independent representative." ${ }^{60}$

While a change in the domestic legislation to this effect would be welcomed by all who are interested in children's rights, it looks out of place in a human rights charter which purports to produce rights:

"drafted in general terms, setting out basic principles for public bodies in performing their duties but also allowing a good deal of flexibility in the way in which these principles are implemented. .."61

The same basic outcome might have been achieved through robust enforcement of the right not to be denied education, read together with the child's right to participate in decision-making. However, perhaps the most striking difference is the fact that, while the children's rights proposed go well beyond anything which might be considered to reflect "the particular circumstances of Northern Ireland", in the education chapter, attention seems to be have been confined to dealing with the aspects of the system which have previously proved contentious.

\section{CONCLUSION}

The NIHRC has acknowledged that its proposals will not provide answers to all Northern Ireland's human rights dilemmas - the Holy Cross protests being the obvious example in the area of education. However the proposals do contain some significant extensions to the ECHR which would enable fundamental human rights principles to be deployed in the education system when change is being considered and in the resolution of the disputes which will inevitably arise. Much is to be welcomed but most might have been predicted. In some ways, the opportunity for fundamental change could be lost by the focus on some of the obvious areas of contention within the system. $^{62}$ It may be that certain interests (such as the Irish medium and integrated sectors and the children's rights lobby) were actively engaged with the Bill of Rights process from the beginning and therefore were well placed to influence the initial consultation. It is to be hoped that other education interests will now enter the debate and what will emerge ultimately is a broadly-based document which will provide the NIHRC's stated aspiration of providing "a rallying point for all sections of the community."

60 Chapter 11(i) 3.

61 Summary, Introduction.

62 See discussion on Proposal 11(a)(3). 